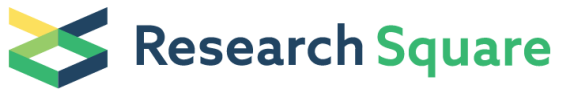 \\ Preprints are preliminary reports that have not undergone peer review. \\ They should not be considered conclusive, used to inform clinical practice, \\ or referenced by the media as validated information.
}

\section{Integrated Transmission Assessment Surveys (iTAS) of Lymphatic Filariasis and Onchocerciasis in Cross River, Taraba and Yobe States Nigeria.}

\section{Ifeoma $\mathbf{N}$ Anagbogu}

Independent Consultant, Abuja, Former NTD National Coordinator, Federal Ministry of Health, Abuja.

\section{Yisa A Saka}

Independent Consultant, Lagos, Former NTD National Coordinator, Federal Ministry of Health, Abuja.

Olabanji Ahmed Surakat ( $\square$ olabanji.surakat@uniosun.edu.ng)

Osun State University https://orcid.org/0000-0002-2382-3857

\section{Chukwu Okoronkwo}

Federal Ministry of Health

\section{Emmanuel Davies}

Federal Ministry of Health

\section{Philip Oyale}

Federal Ministry of Health

\section{Uwem Ekpo}

Federal University of Agriculture Abeokuta

\section{Uche Amazigo}

Independent Consultant, Enugu, Former Director, African Programme for Onchocerciasis Control, Ouagadougou Nigeria.

Kira Barbre

Neglected Tropical Diseases Support Center, The Task Force for Global Health, Atlanta, GA, USA.

\section{Mike lgbe}

Federal Ministry of Health

\section{Audrey Nyior}

Federal Ministry of Health

\section{Jacob Solomon}

Federal Ministry of Health

\section{Gideon Ntuen}

Federal Ministry of Health

\section{Zaiya Umar}

Federal Ministry of Health

\section{Research}

Keywords: LGAs, Pre-TAS, iTAS, MAM, Onchocerciasis, Lymphatic filariasis, Nigeria

Posted Date: August 24th, 2021

DOl: https://doi.org/10.21203/rs.3.rs-815224/v1

License: (c) (1) This work is licensed under a Creative Commons Attribution 4.0 International License. Read Full License 


\section{Abstract}

Background: Integrated Transmission Assessment Surveys (iTAS) has been recommended for evaluation of transmission of both lymphatic filariasis and onchocerciasis, as the prevalence of both diseases move toward their respective elimination targets in Nigeria. Therefore, iTAS was conducted between May and December 2017 in five local government areas also known as implementing units (IU) in Cross River, Taraba and Yobe States of Nigeria.

Methods: TAS comprises of two phases: The Pre-iTAS and the iTAS. Three states (Cross-Rivers, Taraba and Yobe) comprising of 5 LGAs and 20 communities that have completed 5 rounds of combined treatment with ivermectin and albendazole for LF and 12 rounds of ivermectin were selected for the study. For the Pre-iTAS, Filariasis Test Strip (FTS) and Biplex rapid diagnostic test (Ov16/Wb123 RDT) were used to test 2000 children from age 5-9 for onchocerciasis and 300 persons aged 10 years and above for LF. For the iTAS, only LGAs where all sampled communities during the Pre-iTAS were with less than $2 \%$ antigenemia prevalence for LF was selected.

Results: Four out of the five LGAs passed the pre-iTAS except Ikom LGA which had an antigenemia prevalence of more than $2 \%$. A total of 11531 school-aged children were tested for LF and onchocerciasis across the four LGAs. Bade tested 2,873, Bekwara 2,622, Gashaka 3,026 and Karim Lamido 3,010 from 148 schools. For LF prevalence, zero prevalence was recorded for Bade and Karim Lamido while Bekwara and Gashaka recorded $0.19 \%$ and $0.23 \%$ respectively using FTS. The same was not recorded using Ov16/Wb123 biplex as Bade, Bekwara, Gashaka and Karim Lamido recorded $0.03 \%, 0.53 \%, 0.43 \%$ and $0.03 \%$ respectively. For onchocerciasis prevalence, Bade and Karim Lamido recorded zero prevalence while Bekwara, Gashaka recorded 3.09\% and 1.75\% respectively.

Conclusion: This study has provided additional information on the current burden of onchocerciasis and lymphatic filariasis (LF) in the 4 IUs sampled where MAM for both infections has been ongoing for years. The study identifies that LF-MAM can be safely stopped in all 4 of the studied IUs. However, MAM for onchocerciasis needs to continue, although this may pose a challenge for LF surveillance. Based on the preliminary results from all four sites, this study has fulfilled the primary objective of determining the programmatic feasibility of an integrated transmission assessment survey (iTAS), to be used to simultaneously assess onchocerciasis and LF prevalence in areas co-endemic for the two infections that have completed the recommended treatment for one or both infections, and to make decisions on how to proceed.

\section{Background}

Lymphatic filariasis (LF) and onchocerciasis are infections caused by microscopic nematodes Wuchereria bancrofti and Onchocerca volvulus transmitted respectively by mosquitoes and black flies of the genus Simulium (1). LF is found to be endemic in 73 countries with a projected 1.1 billion individuals at risk while, at least, 169 million people are estimated to be at risk of infection with onchocerciasis in 31 countries in Africa require mass administration of medicine (MAM) (2).

Infection with LF leads to blockages of the lymphatic system, which result in swellings of limbs and genitals (lymphedema, elephantiasis, and hydrocele in men), and painful recurrent bacterial infections. The control approach in Africa is MAM (or mass drug administration - MDA) of single-dose combination therapy with albendazole and ivermectin or diethylcarbamazine (3). When given for an estimated period of five to six years with an annual minimum therapeutic coverage of $65 \%$, MAM can interrupt transmission of $W$. bancrofti in a population. A total of 583 local government areas (LGAs) are endemic for LF in Nigeria, with 567 LGAs conducting at least one MAM round and 30 LGAs in post-MAM surveillance. However, there are 16 LGAs yet to start MAM due to funding challenges (4).

Onchocerciasis, on the other hand, causes intense skin disease and may eventually result in blindness. Control and elimination efforts focus on MAM using ivermectin, with sporadic vector control where conditions are favourable $(4,5)$. Nigeria has the highest burden of onchocerciasis globally with about 50 million persons in over 40,000 communities at risk of infection, accounting for about $40 \%$ of the global population at risk. In Nigeria, a total of 480 LGAs are targeted for the elimination of onchocerciasis transmission with over $85 \%$ geographic coverage currently being achieved (6). 
The African Programme for Onchocerciasis Control (APOC), which replaced the Onchocerciasis Control Programme (OCP), supported the control of onchocerciasis through annual or six-monthly ivermectin-based MAM as well as vector control in selected foci (7). When treatment occurs at least once a year for about 15 years or more, it is possible to interrupt transmission (8). APOC goals transitioned from control to elimination of onchocerciasis after a study, which took place in Mali and Senegal, and published in 2009 provided the first evidence that the elimination of onchocerciasis was feasible in Africa with ivermectin distribution alone (9).

National LF programs focus on a series of critical steps following standardized WHO protocols: i) mapping to determine endemicity, ii) implementation of MAM with a minimum of $65 \%$ treatment coverage once yearly for at least five years in endemic areas, iii) a survey to determine whether prevalence is low enough for MAM to stop, iv) post-MAM surveillance, and v) validation of elimination of LF as a public health problem (10).

In most communities in Nigeria, there is substantial overlap between LF and onchocerciasis. Both diseases overlap in 366 LGAs in Nigeria. In those co-endemic LGAs, ivermectin is commonly distributed with albendazole during mass administration of medicines campaigns. Filariasis programs in countries have typically functioned vertically and, until a few years ago in Nigeria, the decision to start MAM was often made for each disease independently without taking into account the endemicity of the other disease.

As the country begins to reach a sufficient number of effective rounds of MAM, a decision needs to be made on whether the implementation unit (IU) can safely stop MAM for one infection without compromising the success of both elimination programs. The IU in the country context is the local government areas LGAs. An integrated assessment for both filariasis could therefore be a cost-effective tool to make joint stop decisions for lymphatic filariasis and onchocerciasis. One integrated survey would assess the serological prevalence of both diseases by targeting young children as indicators of recent exposure to the two parasites.

Based on this background, the study set out to determine the programmatic feasibility of an integrated LF transmission assessment survey (iTAS) and onchocerciasis epidemiological evaluation for simultaneous assessment of both diseases in coendemic areas, which have completed the recommended period of treatment.

\section{Methods}

\section{Study design, selection of study sites and sampling strategies}

The study was divided into two phases: The Pre-iTAS and the main iTAS. The initial phase (Pre-iTAS) was subjected to the WHO's eligibility criteria for conducting LF Transmission Assessment Surveys (TAS) which qualifies an implementing unit with less than $2 \%$ antigenemia prevalence to pass TAS $(11,3)$.

\section{Pre-iTAS}

A total of 5 LGAs (Implementation Units - IUs) in 3 States were selected for the Pre-iTAS, namely Ikom and Bekwara LGAs in Cross River State, Gashaka and Karim-Lamido LGAs in Taraba State, and Bade LGA in Yobe State. The selected LGAs had successfully conducted a minimum of 5 effective rounds of ivermectin and albendazole combined treatment for LF, as well as more than 12 effective rounds of ivermectin treatment alone for onchocerciasis. In each IU, two sites were selected for Pre-iTAS which focused on LF. The two sites comprised of one LF sentinel site with a high baseline prevalence for LF and one onchocerciasis sentinel site founded on a high risk of onchocerciasis infection at baseline REMO. Each of the onchocerciasis sentinel sites served as a spotcheck site for either infection.

To assess interruption for LF, a total of 300 persons aged 10 years and above were selected by convenience sampling in the 2 sentinel sites selected in the IUs (one LF sentinel site and one spot-check site). They were tested for both LF and onchocerciasis using FTS and Biplex RDT (Ov16/Wb123).

For the onchocerciasis assessment, 4 communities were selected in each IU which included the LF sentinel site and spot-check site as above, as well as 2 additional first-line villages. A total of 100 children aged $5-9$ years were sampled in each of the 4 communities through convenience sampling and tested for both LF and onchocerciasis using FTS and Biplex RDT (Ov16/Wb123). 
Table 1: Communities selected for Pre-iTAS in the IUs/LGAs

\begin{tabular}{|c|c|c|}
\hline State & LGA (IU) & Communities \\
\hline \multirow[t]{8}{*}{ Cross River } & \multirow[t]{4}{*}{ Bekwara } & Afrike \\
\hline & & Itekpa \\
\hline & & Atibulum \\
\hline & & NyanaOlim \\
\hline & \multirow[t]{4}{*}{ Ikom } & Agbaragba \\
\hline & & Balep \\
\hline & & Etikpe \\
\hline & & Ukpochi \\
\hline \multirow[t]{8}{*}{ Taraba } & \multirow[t]{4}{*}{ Gashaka } & Gashaka \\
\hline & & Mayo Selbe \\
\hline & & Nybar \\
\hline & & Shinbon \\
\hline & \multirow[t]{4}{*}{ Karim Lamido } & Bandawa \\
\hline & & Gwomu \\
\hline & & Kodei \\
\hline & & Panya \\
\hline \multirow[t]{4}{*}{ Yobe } & \multirow[t]{4}{*}{ Bade } & Dagona \\
\hline & & Gafiwa \\
\hline & & Gwio Kura \\
\hline & & Tagali \\
\hline
\end{tabular}

\section{ITAS}

The qualification for TAS was that all the selected sites in an IU achieve less than $2 \%$ antigenemia prevalence for LF in each of the five LGAs. Using random cluster sampling, a minimum of 30 schools were selected from each LGA from a sampling frame of all the primary schools in the LGA. A total of 2,500 to 2,700 participants aged 5 - 9 years were included in each LGA. Target grades chose to represent the majority of pupils aged 5-9 were Grades 1 - 3 for public schools and 1 - 4 for private schools Table 2 .

Table 2: Schools selected for iTAS in the IUs/LGAs

\begin{tabular}{llll} 
State & LGA (IU) & Total number of schools & Number of persons planned to be tested \\
\hline Cross River & Bekwarra & 34 & 2,590 \\
\hline \multirow{2}{*}{ Taraba } & Gashaka & 30 & 2,500 \\
\cline { 2 - 4 } & Karim Lamido & 52 & 2,700 \\
\hline \multirow{2}{*}{ Yobe } & Bade & 30 & 2,700
\end{tabular}

Figures $1-4$ show the location of the selected schools in the three States. 
From the records, communities with 12-24 treatment rounds for onchocerciasis and 5-7 treatment rounds for LF were selected to participate in the study in Cross River, Taraba and Yobe State, Nigeria. All pupils in the target grades in the selected schools were enrolled for the survey using simple random selection.

\section{Diagnostic testing}

Participants were tested using SD BIOLINE Oncho/LF IgG4 Biplex RDT (Ov16 and Wb123) and the Filariasis Test Strip (FTS). The Biplex is a rapid test that detects antibodies against both the 0 . volvulus Ov16 and the W. bancrofti Wb123 antigens. The FTS is an antigen test currently recommended by WHO for use for LF tests.

\section{Data Analysis}

Frequencies and 95\% confidence interval (Cl) for LF antigenemia, Wb123 and Ov16 positivity were determined using SPSS 21 (IBM Corp, Armonk, NY, USA). The $95 \% \mathrm{Cl}$ of the prevalence or frequencies was calculated by using a binomial confidence interval exact test calculator.

\section{Results}

\section{Pre-iTAS.}

\section{Demographic characteristics of study participants during Pre-ITAS}

A total of 5,312 participants from 20 communities were enrolled on the study. Of the total enrolled, $(98 \% 5,244)$ persons were tested across the 5 LGAs (Table 3). The study demographics showed that 2,829 (53.95\%) of the study participants were female and 2,415 (46.05\%) were male. Of the number tested, 2,101 (40.06\%) were children aged 5 - 9 years.

Table 3: Distribution of study participants by age and sex 


\begin{tabular}{|c|c|c|c|c|c|c|c|c|c|c|}
\hline \multirow[t]{2}{*}{$\mathrm{S} / \mathrm{N}$} & \multirow[t]{2}{*}{ State } & \multirow[t]{2}{*}{ LGA } & \multirow[t]{2}{*}{ Name of Community } & \multicolumn{3}{|c|}{$\begin{array}{l}\text { No. sampled } \\
\text { (5 yrs <10yrs) }\end{array}$} & \multicolumn{3}{|c|}{$\begin{array}{l}\text { No. Sampled } \\
(\geq 10 \mathrm{yrs})\end{array}$} & \multirow[t]{2}{*}{ Total sampled } \\
\hline & & & & M & $F$ & Total & $M$ & $\mathrm{~F}$ & Total & \\
\hline 1 & \multirow[t]{4}{*}{ Yobe } & \multirow[t]{4}{*}{ Bade } & Dagona & 54 & 46 & 100 & 99 & 211 & 310 & 410 \\
\hline 2 & & & Gafiwa & 58 & 58 & 116 & 0 & 0 & 0 & 116 \\
\hline 3 & & & Tagali & 54 & 51 & 105 & 153 & 158 & 311 & 416 \\
\hline 4 & & & Gwio Kura & 47 & 58 & 105 & 0 & 0 & 0 & 105 \\
\hline \multicolumn{4}{|c|}{ Sub Total } & 213 & 213 & 426 & 252 & 369 & 621 & 1047 \\
\hline 5 & \multirow[t]{4}{*}{ Cross River } & \multirow[t]{4}{*}{ Ikom } & Ukpochi & 47 & 55 & 102 & 0 & 0 & 0 & 102 \\
\hline 6 & & & Agbaragba & 63 & 38 & 101 & 0 & 0 & 0 & 101 \\
\hline 7 & & & Etikpe & 57 & 53 & 110 & 144 & 154 & 298 & 408 \\
\hline 8 & & & Balep & 56 & 60 & 116 & 166 & 139 & 305 & 421 \\
\hline \multicolumn{4}{|c|}{ Sub Total } & 223 & 206 & 429 & 310 & 293 & 603 & 1032 \\
\hline 9 & \multirow[t]{4}{*}{ Cross River } & \multirow[t]{4}{*}{ Bekwara } & Nyanya-Ulim & 49 & 52 & 101 & 0 & 0 & 0 & 101 \\
\hline 10 & & & Atibulum & 49 & 51 & 100 & 0 & 0 & 0 & 100 \\
\hline 11 & & & Itekpa & 46 & 55 & 101 & 73 & 215 & 288 & 389 \\
\hline 12 & & & Afrike-Okpeche & 49 & 51 & 100 & 86 & 218 & 304 & 404 \\
\hline \multicolumn{4}{|c|}{ Sub Total } & 193 & 209 & 402 & 159 & 433 & 592 & 994 \\
\hline 13 & \multirow[t]{4}{*}{ Taraba } & \multirow[t]{4}{*}{ Gashaka } & Shinbon & 29 & 32 & 61 & 0 & 0 & 0 & 61 \\
\hline 14 & & & Gashaka & 47 & 46 & 93 & 0 & 0 & 0 & 93 \\
\hline 15 & & & Mayo-Selbe & 115 & 81 & 196 & 249 & 102 & 351 & 547 \\
\hline 16 & & & Nyabar & 38 & 32 & 70 & 160 & 221 & 381 & 451 \\
\hline \multicolumn{4}{|c|}{ Sub Total } & 229 & 191 & 420 & 409 & 323 & 732 & 1152 \\
\hline 17 & \multirow[t]{4}{*}{ Taraba } & \multirow[t]{4}{*}{ K/Lamido } & Bandawa & 53 & 58 & 111 & 103 & 207 & 310 & 421 \\
\hline 18 & & & Panya 0 & 51 & 52 & 103 & 130 & 165 & 295 & 398 \\
\hline 19 & & & Gwomu 0 & 52 & 52 & 104 & 0 & 0 & 0 & 104 \\
\hline 20 & & & Kodei 0 & 38 & 68 & 106 & 0 & 0 & 0 & 106 \\
\hline \multicolumn{4}{|c|}{ Sub Total } & 194 & 230 & 424 & 233 & 372 & 605 & 1029 \\
\hline \multicolumn{4}{|c|}{ TOTAL } & 1052 & 1049 & 2101 & 1363 & 1780 & 3,143 & 5,244 \\
\hline
\end{tabular}

\section{LF antigenemia prevalence during Pre-iTAS}

A total of 5,191 valid tests was conducted using FTS. From the valid tests, an overall antigenemia prevalence of $0.5 \%$ was recorded across all the study areas. Among the LGAs, the highest antigenemia prevalence of $1 \%(10 / 1,026)$ was recorded in Ikom LGA in Cross River State, followed by Gashaka LGA $(7 / 1,152)$ in Taraba State and Bekwarra LGA $(5 / 1,011)$ in Cross River State both recording $0.6 \%$ prevalence respectively (Table 4). Among the communities surveyed, Agbaragba in Ikom LGA had the highest prevalence of $5.9 \%(6 / 101)$. Karim Lamido LGA recorded no positive case for LF using the FTS. In total, fourteen communities across all study areas recorded zero antigenemia positive cases for LF using the FTS.

Table 4: LF prevalence with FTS by age group 


\begin{tabular}{|c|c|c|c|c|c|c|c|}
\hline State & LGA & $\begin{array}{l}\text { Name of } \\
\text { Community }\end{array}$ & $\begin{array}{l}\text { Total } \\
\text { sampled }\end{array}$ & $\begin{array}{l}\text { Total valid } \\
\text { FTS }\end{array}$ & $\begin{array}{l}\text { FTS +ve } 5 \text { - } \\
<10 \text { yrs }\end{array}$ & $\begin{array}{l}\text { FTS +ve } 10 \text { Yrs\& } \\
\text { above }\end{array}$ & $\begin{array}{l}\text { Total FTS } \\
\text { +ve }\end{array}$ \\
\hline \multirow[t]{4}{*}{ Yobe } & \multirow[t]{4}{*}{ Bade } & Dagona & 410 & 400 & 0 & 0 & 0 \\
\hline & & Gafiwa & 116 & 116 & 0 & 0 & 0 \\
\hline & & Tagali & 416 & 380 & $1(0.3)$ & $2(0.5)$ & $3(0.8)$ \\
\hline & & Gwio Kura & 105 & 105 & 0 & 0 & 0 \\
\hline Sub Total & & & 1047 & 1001 & $1(0.1)$ & $2(0.2)$ & $3(0.3)$ \\
\hline \multirow{4}{*}{$\begin{array}{l}\text { Cross } \\
\text { River }\end{array}$} & \multirow[t]{4}{*}{ Ikom } & Ukpochi & 102 & 102 & 0 & 0 & 0 \\
\hline & & Agbaragba & 101 & 101 & $6(5.9)$ & 0 & $6(5.9)$ \\
\hline & & Etikpe & 408 & 405 & 0 & 0 & 0 \\
\hline & & Balep & 421 & 418 & 0 & $4(1.0)$ & $4(1.0)$ \\
\hline Sub Total & & & 1032 & 1026 & $6(0.6)$ & $4(0.4)$ & $10(1.0)$ \\
\hline \multirow{4}{*}{$\begin{array}{l}\text { Cross } \\
\text { River }\end{array}$} & \multirow[t]{4}{*}{ Bekwara } & Nyanya-Ulim & 101 & 101 & 0 & 0 & 0 \\
\hline & & Atibulum & 100 & 100 & 0 & 0 & 0 \\
\hline & & Itekpa & 407 & 407 & $2(0.5)$ & $4(1.0)$ & $6(1.5)$ \\
\hline & & Afrike-Okpeche & 404 & 403 & 0 & 0 & 0 \\
\hline Sub Total & & & 1012 & 1011 & $2(0.2)$ & $4(0.4)$ & $6(0.6)$ \\
\hline \multirow[t]{4}{*}{ Taraba } & \multirow[t]{4}{*}{ Gashaka } & Shinbon & 61 & 61 & 0 & 0 & 0 \\
\hline & & Gashaka & 93 & 93 & 0 & 0 & 0 \\
\hline & & Mayo-Selbe & 547 & 547 & $1(2.1)$ & $2(0.4)$ & $3(0.6)$ \\
\hline & & Nyabar & 451 & 451 & 0 & $4(0.9)$ & $4(0.9)$ \\
\hline Sub Total & & & 1152 & 1152 & $1(0.1)$ & $6(0.5)$ & $7(0.6)$ \\
\hline \multirow[t]{4}{*}{ Taraba } & \multirow[t]{4}{*}{ K/Lamido } & Bandawa & 421 & 395 & 0 & 0 & 0 \\
\hline & & Panya 0 & 398 & 396 & 0 & 0 & 0 \\
\hline & & Gwomu 0 & 104 & 104 & 0 & 0 & 0 \\
\hline & & Kodei O & 106 & 106 & 0 & 0 & 0 \\
\hline Sub Total & & & 1029 & 1001 & 0 & 0 & 0 \\
\hline
\end{tabular}

\section{LF and onchocerciasis seroprevalence using SD Bioline Biplex RDT during Pre-iTAS}

Using the Biplex, a total of $31 \mathrm{LF}$ seropositive cases $(0.01 \%)$ were detected from the valid tests in all the 20 communities visited for all ages. The highest number (19) was recorded in Bekwarra LGA in Cross River State while Bade LGA in Yobe State had zero seropositive cases. Only 2 communities had LF seropositive cases (3 each) for children less than 10 years - Agbaragba community in Ikom LGA (3.0\%) and Gashaka in Taraba State (3.2\%). A total of 317 onchocerciasis seropositive cases (6.02\%) were detected from the valid tests using the Biplex in all the 20 communities visited for all ages. The highest number (142) was recorded in Ikom LGA, followed closely by Bekwarra LGA (126) both in Cross River State (Table 5). Bade LGA in Yobe State and Karim Lamido in Taraba State had no seropositive cases. Seven (7) communities had onchocerciasis seropositive cases by Biplex for children less than 10 years, with the highest seroprevalence of $8.2 \%$ being recorded in Shibon community in Gashaka LGA of Taraba State.

Figures 5 and 6 show Ov16 prevalence in Bekwerra (Cross River) and Gashaka (Taraba) 
Table 5: Seroprevalence of onchocerciasis and LF with Biplex by age group

\begin{tabular}{|c|c|c|c|c|c|c|c|c|c|c|}
\hline \multirow[t]{2}{*}{ State } & \multirow[t]{2}{*}{ LGA } & \multirow[t]{2}{*}{$\begin{array}{l}\text { Name of } \\
\text { community }\end{array}$} & \multirow[t]{2}{*}{$\begin{array}{l}\text { Total } \\
\text { sampled }\end{array}$} & \multirow{2}{*}{$\begin{array}{l}\text { Total } \\
\text { valid } \\
\text { Biplex }\end{array}$} & \multicolumn{2}{|c|}{ Biplex +ve 5<10 } & \multicolumn{2}{|c|}{$\begin{array}{l}\text { Biplex +ve } 10 \text { yrs\& } \\
\text { above }\end{array}$} & \multicolumn{2}{|c|}{ Total Biplex +ve } \\
\hline & & & & & Oncho & LF & Oncho & LF & Oncho & LF \\
\hline \multirow[t]{5}{*}{ Yobe } & \multirow[t]{5}{*}{ Bade } & Dagona & 410 & 410 & 0 & 0 & 0 & 0 & 0 & 0 \\
\hline & & Gafiwa & 116 & 116 & 0 & 0 & 0 & 0 & 0 & 0 \\
\hline & & Tagali & 416 & 415 & 0 & 0 & 0 & 0 & 0 & 0 \\
\hline & & Gwio Kura & 105 & 105 & 0 & 0 & 0 & 0 & 0 & 0 \\
\hline & & Total & 1047 & 1046 & 0 & 0 & 0 & 0 & 0 & 0 \\
\hline \multirow{5}{*}{$\begin{array}{l}\text { Cross } \\
\text { River }\end{array}$} & \multirow[t]{5}{*}{ Ikom } & Ukpochi & 102 & 102 & 0 & 0 & 0 & 0 & 0 & 0 \\
\hline & & Agbaragba & 101 & 101 & $1(1.0)$ & $\begin{array}{l}3 \\
(3.0)\end{array}$ & 0 & 0 & $1(1.0)$ & $3(3.0)$ \\
\hline & & Etikpe & 408 & 408 & $2(0.5)$ & 0 & $70(17.2)$ & $1(0.3)$ & 72(17.7) & $1(0.3)$ \\
\hline & & Balep & 421 & 421 & $1(0.24)$ & 0 & $68(16.2)$ & 0 & $69(16.4)$ & 0 \\
\hline & & Total & 1032 & 1032 & $4(0.4)$ & $3(0.3)$ & $138(13.4)$ & $1(0.0 .1)$ & $142(13.8)$ & $4(0.4)$ \\
\hline \multirow{5}{*}{$\begin{array}{l}\text { Cross } \\
\text { River }\end{array}$} & \multirow[t]{5}{*}{ Bekwara } & Nyanya-Ulim & 101 & 100 & $4(4)$ & 0 & 0 & 0 & $4(4)$ & 0 \\
\hline & & Atibulum & 100 & 100 & 0 & 0 & 0 & 0 & 0 & 0 \\
\hline & & Itekpa & 407 & 407 & 0 & 0 & $27(6.6)$ & $4(1.0)$ & $27(6.6)$ & $4(1.0)$ \\
\hline & & AfrikeOkpeche & 404 & 404 & 0 & 0 & $95(23.5)$ & $15(3.7)$ & $95(23.5)$ & $15(3.7)$ \\
\hline & & Total & 1012 & 1011 & $4(0.4)$ & 0 & $122(12.1)$ & 19(1.9) & $126(12.5)$ & 19(1.9) \\
\hline \multirow[t]{5}{*}{ Taraba } & \multirow[t]{5}{*}{ Gashaka } & Shinbon & 61 & 61 & $5(8.2)$ & 0 & 0 & 0 & $5(8.2)$ & 0 \\
\hline & & Gashaka & 93 & 93 & 0 & $3(3.2)$ & 0 & 0 & 0 & $3(3.2)$ \\
\hline & & Mayo-Selbe & 547 & 547 & $4(0.7)$ & 0 & $10(1.8)$ & 0 & $10(1.8)$ & 0 \\
\hline & & Nyabar & 451 & 451 & $3(0.7)$ & 0 & $31(6.9)$ & $3(0.7)$ & $34(7.5)$ & $3(0.7)$ \\
\hline & & Total & 1152 & 1152 & $12(1.0)$ & $3(0.3)$ & $41(3.6)$ & $3(0.3)$ & $49(4.3)$ & $6(0.5)$ \\
\hline \multirow[t]{5}{*}{ Taraba } & \multirow{5}{*}{$\begin{array}{l}\text { Karim } \\
\text { Lamido }\end{array}$} & Bandawa & 421 & 421 & 0 & 0 & 0 & 2 & 0 & 2 \\
\hline & & Panya 0 & 398 & 398 & 0 & 0 & 0 & 0 & 0 & 0 \\
\hline & & Gwomu 0 & 104 & 104 & 0 & 0 & 0 & 0 & 0 & 0 \\
\hline & & Kodei 0 & 106 & 106 & 0 & 0 & 0 & 0 & 0 & 0 \\
\hline & & Total & 1029 & 1029 & 0 & 0 & 0 & $2(0.2)$ & 0 & $2(0.2)$ \\
\hline
\end{tabular}

iTAS.

The results of the Pre-FTAS in the studied LGAs indicated that most of the communities had an antigenemia prevalence of less than $2 \%$. However, Ikom LGA could not proceed to iTAS due to the $5.9 \%$ prevalence recorded among children who are considered serological markers of new infection in the Agbaragba community. The (iTAS) phase employed random sampling to select a total of 148 schools to give an equal chance of selection for each school and eliminate bias. 
A total of 148 schools were visited and sampled across 4 LGAs. Of these, 131 (88.51\%) were classified as rural while 17 (11.49\%) were urban. All (100\%) communities where these schools were located had conducted onchocerciasis MAM for $17-21$ years and LF MAM for $5-7$ years. Total enrolments in the sampled schools within the targeted grades were 17,707. Bade LGA had the highest (48.53\%) number of enrolments (Table 6). 11,564 pupils were registered for the study with the highest number being recorded in Gashaka LGA (Table 7). Both genders were equally represented with females being 5,805 (50.20\%) and males 5,759 (49.80\%) (Table 7). The grade with the highest number of registered pupils was Grade 1 with 4,816 (41.75\%), followed by Grade 2 with 3,344 (28.99\%), and then Grade 3 with 3,254 (28.21\%). Expectedly, Grade 4 had the lowest number registered with 120 (1.04\%). Age group $<10$ years were $9,656(83.50 \%)$ and the age group $\geq 10$ years were $1,908(16.50 \%)$.

Table 6: Schools visited and the respective grade enrolments

\begin{tabular}{lllllll} 
LGA (IU) & No of Schools Sampled & \multicolumn{7}{l}{ Number Enrolled in Targeted Grades } \\
\cline { 3 - 4 } & & Grade 1 & Grade 2 & Grade 3 & Grade 4 & Total \\
\hline Bade & 30 & 2,655 & 3,042 & 2,803 & 93 & 8,593 \\
\hline Bekwara & 34 & 1,109 & 900 & 992 & 77 & 3,078 \\
\hline Gashaka & 30 & 1,325 & 855 & 846 & 0 & 3,026 \\
\hline Karim Lamido & 52 & 1,321 & 777 & 912 & 0 & 3,010 \\
\hline Total & $\mathbf{1 4 8}$ & $\mathbf{6 , 4 1 0}$ & $\mathbf{5 , 5 7 4}$ & $\mathbf{5 , 5 5 3}$ & $\mathbf{1 7 0}$ & $\mathbf{1 7 , 7 0 7}$
\end{tabular}

Table 7: Number of pupils tested by gender, grade and age group

\begin{tabular}{|c|c|c|c|c|c|c|c|}
\hline \multirow[t]{2}{*}{ LGA (IUs) } & \multicolumn{3}{|c|}{ Number Tested by Gender } & \multicolumn{4}{|c|}{ Number Tested by Age Group } \\
\hline & Male & Female & Total & $<5$ years & 5 - 9 years & $>9$ years & Total \\
\hline Bade & 1,387 & 1,488 & 2,875 & 0 & 2,388 & 487 & 2,875 \\
\hline Bekwara & 1,343 & 1,279 & 2,622 & 0 & 2,222 & 400 & 2,622 \\
\hline Gashaka & 1,561 & 1,465 & 3,026 & 0 & 2,551 & 475 & 3,026 \\
\hline Karim Lamido & 1,438 & 1,572 & 3,010 & 253 & 2241 & 516 & 3010 \\
\hline Total & 5,729 & 5,804 & 11,533 & 253 & 9,402 & 1,878 & 11,533 \\
\hline
\end{tabular}

\section{LF antigenemia prevalence during iTAS}

Twelve (12) LF antigenemia positive cases (0.10\%) were recorded in all the 4 LGAs using the FTS. Six (50\%) of these cases were pupils in Grade 1, one case (8.33\%) in Grade 2, and 5 cases (41.67\%) in Grade 3. No case was recorded in Grade 4. Both sexes had about the same proportions. Gashaka and Bekwerra LGAs had antigenemia prevalence of $0.23 \%$ and $0.19 \%$ respectively while zero prevalence was observed in both Bade and Karim Lamido LGAs. Of the total 12 positive cases, $11(91.67 \%)$ were children $<10$ years old while $1(8.33 \%)$ fell in the $\geq 10 y e a r s$ age group.

\section{LF and onchocerciasis seroprevalence using SD Bioline Biplex RDT during iTAS}

A total of 29 LF seropositive cases $(0.25 \%)$ were recorded from the valid tests using the Biplex in all the 148 schools visited. Of these cases, 12 (41.38\%) were in Grade 1, 7 (24.14\%) in Grade 2, and 10 (34.48\%) in Grade 3. No case was recorded in Grade 4. The majority (19-65.52\%) of the positive cases were male. Bekwerra and Gashaka LGAs had almost the same seroprevalence - $0.53 \%$ and $0.43 \%$ with 14 and 13 cases respectively. Bade and Karim Lamido both had one case each with a seroprevalence of $0.03 \%$. Among the 148 schools sampled, $19(12.84 \%)$ had positive cases $(>0 \%)$ with the highest site-specific prevalence $(7.9 \%)$ observed in Bekwerra LGA. A total of 135 onchocerciasis seropositive cases $(1.17 \%)$ were recorded from the valid tests using the Biplex in the 4 sites (Table 10). Of these, 77 (57.04\%) were male and 58 (42.96\%) female. A total of 99 (73.33\%) seropositive cases were recorded among children $<10$ years and $36(26.67 \%)$ among children $\geq 10$ years. Children in Grade 3 had the highest number of positive 
cases (53 - 39.26\%) followed by those in Grade 2 with 45 (33.33\%) cases, and then children in Grade 1 with 37 cases (27.41\%). Children in Grade 4 recorded zero seropositive cases. Of the four sites, the highest seroprevalence of 3.09\% (81 cases) was recorded in Bekwerra LGA. Bade LGA had zero sero-prevalence. Only 1 positive case $(0.003 \%)$ was observed in Karim Lamido while Gashaka recorded a $1.75 \%$ seroprevalence with 53 cases. Sero-prevalence among those aged $<10$ years was $1.05 \%$ with Bekwerra having $3.02 \%$ seroprevalence and Gashaka $1.22 \%$. Of the 148 schools sampled, 46 (31.08\%) recorded onchocerciasis positive cases and seroprevalence $>0.1 \%$ with the highest site-specific prevalence $(22.86 \%)$ recorded in Gashaka LGA. Twenty-four (24) of those schools were in Bekwerra LGA and 20 schools in Gashaka LGA Five schools (3 in Gashaka LGA and 2 in Bekwerra LGA) had onchocerciasis seroprevalence $>10 \%$.

Table 8: LF antigenemia prevalence with FTS by gender, grade and age group

\begin{tabular}{|c|c|c|c|c|c|c|c|c|c|c|c|c|c|c|}
\hline \multirow[t]{3}{*}{ SN } & \multirow[t]{3}{*}{ LGA } & \multirow{3}{*}{$\begin{array}{l}\text { Total } \\
\text { Tested }\end{array}$} & \multirow{3}{*}{$\begin{array}{l}\text { Total Valid } \\
\text { Tests }\end{array}$} & \multicolumn{9}{|c|}{ FTS Positive } & \multirow{3}{*}{$\begin{array}{l}\text { Total } \\
\text { Positive }\end{array}$} & \multirow{3}{*}{$\begin{array}{l}\text { Prevalence } \\
(\%)\end{array}$} \\
\hline & & & & \multicolumn{3}{|c|}{ Gender } & \multicolumn{4}{|c|}{ Grades } & \multicolumn{2}{|c|}{$\begin{array}{l}\text { Age Group } \\
\text { (Yrs) }\end{array}$} & & \\
\hline & & & & $M$ & $F$ & Total & 1 & 2 & 3 & 4 & $<10$ & $\begin{array}{l}10- \\
14\end{array}$ & & \\
\hline 1 & Bade & 2,875 & 2,873 & 0 & 0 & 0 & 0 & 0 & 0 & 0 & 0 & 0 & 0 & 0.00 \\
\hline 2 & Bekwara & 2,622 & 2,622 & 3 & 2 & 5 & 3 & 0 & 2 & 0 & 5 & 0 & 5 & 0.19 \\
\hline 3 & Gashaka & 3,026 & 3,026 & 4 & 3 & 7 & 3 & 1 & 3 & 0 & 6 & 1 & 7 & 0.23 \\
\hline \multirow[t]{2}{*}{4} & $\begin{array}{l}\text { Karim } \\
\text { Lamido }\end{array}$ & 3,010 & 3,010 & 0 & 0 & 0 & 0 & 0 & 0 & 0 & 0 & 0 & 0 & 0.00 \\
\hline & Total & 11,533 & 11,531 & 7 & 5 & 12 & 6 & 1 & 5 & 0 & 11 & 1 & 12 & 0.10 \\
\hline
\end{tabular}

Table 9: LF seroprevalence with Biplex by gender, grade and age group

\begin{tabular}{|c|c|c|c|c|c|c|c|c|c|c|c|c|c|c|}
\hline \multirow[t]{3}{*}{ SN } & \multirow[t]{3}{*}{ LGA } & \multirow{3}{*}{$\begin{array}{l}\text { Total } \\
\text { Tested }\end{array}$} & \multirow{3}{*}{$\begin{array}{l}\text { Total } \\
\text { Valid Tests }\end{array}$} & \multicolumn{9}{|c|}{ Biplex Positive } & \multirow{3}{*}{$\begin{array}{l}\text { Total } \\
\text { Positive }\end{array}$} & \multirow{3}{*}{$\begin{array}{l}\text { Sero- } \\
\text { Prevalence } \\
\text { (\%) }\end{array}$} \\
\hline & & & & \multicolumn{3}{|c|}{ Gender } & \multicolumn{3}{|c|}{ Grades } & & \multicolumn{2}{|c|}{$\begin{array}{l}\text { Age } \\
\text { Group } \\
\text { (Yrs) }\end{array}$} & & \\
\hline & & & & $M$ & $F$ & Total & 1 & 2 & 3 & 4 & $<10$ & $\begin{array}{l}10- \\
14\end{array}$ & & \\
\hline 1 & Bade & 2,875 & 2,873 & 1 & 0 & 1 & 1 & 0 & 0 & 0 & 1 & 0 & 1 & 0.03 \\
\hline 2 & Bekwarra & 2,622 & 2,622 & 10 & 4 & 14 & 6 & 3 & 5 & 0 & 12 & 2 & 14 & 0.53 \\
\hline 3 & Gashaka & 3,026 & 3,026 & 8 & 5 & 13 & 5 & 4 & 4 & 0 & 8 & 5 & 13 & 0.43 \\
\hline \multirow[t]{2}{*}{4} & $\begin{array}{l}\text { Karim } \\
\text { Lamido }\end{array}$ & 3,010 & 3,010 & 0 & 1 & 1 & 0 & 0 & 1 & 0 & 1 & 0 & 1 & 0.03 \\
\hline & Total & 11,533 & 11,531 & 19 & 10 & 29 & 12 & 7 & 10 & 0 & 22 & 7 & 29 & 0.25 \\
\hline
\end{tabular}

Table 10: Onchocerciasis seroprevalence with Biplex by gender, grade and age group 


\begin{tabular}{|c|c|c|c|c|c|c|c|c|c|c|c|c|c|c|}
\hline \multirow[t]{3}{*}{ SN } & \multirow[t]{3}{*}{ LGA } & \multirow{3}{*}{$\begin{array}{l}\text { Total } \\
\text { Tested }\end{array}$} & \multirow{3}{*}{$\begin{array}{l}\text { Total } \\
\text { Valid Tests }\end{array}$} & \multicolumn{9}{|c|}{ Biplex Positive } & \multirow{3}{*}{$\begin{array}{l}\text { Total } \\
\text { Positive }\end{array}$} & \multirow{3}{*}{$\begin{array}{l}\text { Sero- } \\
\text { Prevalence } \\
\text { (\%) }\end{array}$} \\
\hline & & & & \multicolumn{3}{|c|}{ Gender } & \multicolumn{4}{|c|}{ Grades } & \multicolumn{2}{|c|}{$\begin{array}{l}\text { Age } \\
\text { Group } \\
\text { (Yrs) }\end{array}$} & & \\
\hline & & & & $\mathbf{M}$ & $F$ & Total & 1 & 2 & 3 & 4 & $<10$ & $\begin{array}{l}10- \\
14\end{array}$ & & \\
\hline 1 & Bade & 2,875 & 2,873 & 0 & 0 & 0 & 0 & 0 & 0 & 0 & 0 & 0 & 0 & 0.00 \\
\hline 2 & Bekwarra & 2,622 & 2,622 & 35 & 46 & 81 & 28 & 26 & 27 & 0 & 67 & 14 & 81 & 3.09 \\
\hline 3 & Gashaka & 3,026 & 3,026 & 42 & 11 & 53 & 8 & 19 & 26 & 0 & 31 & 22 & 53 & 1.75 \\
\hline \multirow[t]{2}{*}{4} & $\begin{array}{l}\text { Karim } \\
\text { Lamido }\end{array}$ & 3,010 & 3,010 & 0 & 1 & 1 & 1 & 0 & 0 & 0 & 1 & 0 & 1 & 0.00 \\
\hline & Total & 11,533 & 11,531 & 77 & 58 & 135 & 37 & 45 & 53 & 0 & 99 & 36 & 135 & 1.17 \\
\hline
\end{tabular}

\section{Discussion}

Effective monitoring and evaluation are important throughout the lifespan of the MAM programmes. This is needed to effectively assess whether the infection has been reduced to levels where transmission may be assumed to be no longer sustainable, and recrudescence is unlikely to occur even in the absence of drug intervention (12). Surveillance should target the entire population in an evaluation area or implementation unit. However, due to limited resources and time constraints, a careful selection of sites to be monitored is needed. The preliminary results from the integrated transmission assessment survey (iTAS) conducted with FTS indicate an overall LF antigenemia prevalence of $0.10 \%$ with slight variations among the LGAs (Bade $-0.0 \%$; Bekwerra $-0.19 \%$; Gashaka - $0.23 \%$; and Karim Lamido - 0.0\%). The seroprevalence was not significantly different among the LGAs. Only two schools (both in Gashaka LGA) had antigenemia prevalence $>2 \%$. Zero onchocerciasis sero-prevalence was recorded for Bade and Karim Lamido.

These results are consistent with what was obtained from the Pre-iTAS (except for the onchocerciasis seroprevalence from Bekwerra and Gashaka). Interestingly, the Pre-iTAS LF results from Bekwerra LGA which was close to the $2.0 \%$ seroprevalence criteria to qualify for iTAS had come out better with a $0.19 \%$ seroprevalence in the subsequent iTAS, thus justifying the decision to include the LGA for iTAS. This suggests that for LF, Pre-TAS LGAs that have results hovering below or above the $2 \%$ antigenemia prevalence should be considered for iTAS.

Based on the WHO guidelines (3), 4 LGAs were deemed to have passed TAS for LF. There are, however, indications of 'hotspots' schools with prevalence $>2 \%$ - in Bekwerra and Gashaka, although the small sample size may have accounted for the relatively high seroprevalence recorded in those schools. It is understood that MAM will still be carried out in the LGAs during the year of study irrespective of the outcomes of the iTAS. Subject to availability of resources, however, it will be suitable to conduct additional treatment campaigns targeted at the 'hotspot' schools and to further conduct tests following the second round of treatment to determine whether there is transmission is ongoing.

The Wb123/Ov16 Biplex results suggest that transmission of onchocerciasis infection may have been interrupted in Bade and Karim Lamido LGAs, given the zero seroprevalence recorded during iTAS. This is further corroborated to a large extent by similar results from the Pre-ITAS. Nevertheless, these results are not sufficient to recommend a stop/halt for onchocerciasis MAM in any of these LGAs. The Biplex serological test as a whole is not approved yet as a tool for surveillance. The Ov16 RDT serological test, which has been approved for surveillance, is not to be solely utilized in deciding to stop onchocerciasis MAM. In Nigeria, the State is regarded as the transmission zone and the evaluation unit, and the decision to stop onchocerciasis MAM will require a statewide assessment followed by entomological evaluation of adult black flies to determine $<1 / 2000$ infectivity rate before pronouncing stoppage of MAM (4).

The current status of LF recorded in the studied LGAs is expected given the treatment coverage of over $85 \%$ achieved annually which had initially qualified them for Pre-iTAS, the low pre-intervention antigenemia prevalence of $<10 \%$ in 3 out of the 5 LGAs 
studied having $\leq 2.0 \%$, and the long history of treatment with ivermectin ranging between 17-21 years. There exists a possibility of the indirect microfilaricidal effect of ivermectin treatment for onchocerciasis interrupting transmission of LF (13).

The relatively high level of transmission of onchocerciasis observed in Gashaka raises concern. Although the pre-intervention endemicity and outcomes of previous epidemiological assessments using skin snips had been high (14), the impact of mass treatment over the years ought to have been observed in the pattern of endemicity. Similarly, the relatively high transmission of onchocerciasis in Bekwerra LGA is unexpected due to the low pre-intervention endemicity and the long history of annual treatments in the LGA. It is noticeable that transmission remains ongoing in both Bekwerra and Gashaka due to seroprevalence recorded among children population, who are serological markers of a new infection. These may be due to inadequate compliance to (attrition, fatigue) annual treatment by the target populations in those areas. Consequently, the strengthening of MDA interventions and the supervision process is of critical importance.

Ov16 results from both the pre-iTAS and iTAS brought out a few important issues. Results for Ov16 during the iTAS indicated that prevalence increased with age. Given this outcome, a sampling strategy that includes children ages 5-9 compared to ages 6-7 as in traditional LF TAS resulted in a more conservative pre-stop assessment. WHO may therefore wish to look for more evidence for the inclusion of this age bracket in future assessments. The pre-iTAS results indicated that purposeful selection of first-line villages was insufficient at identifying the sites with the highest Ov16 prevalence by RDT in 5-9year olds, suggesting that random sampling may be necessary to identify sites with the potential transmission.

\section{Conclusion}

This study has provided additional information on the current burden of Onchocerciasis and Lymphatic Filariasis (LF) in the 4 IUs sampled where MAM for both infections has been ongoing for years. The study identifies that LF-MAM can be safely stopped in all 4 of the studied IUs. However, MAM for onchocerciasis needs to continue, although this may pose a challenge for LF surveillance. Based on the preliminary results from all four sites, this study has fulfilled the primary objective of determining the programmatic feasibility of an integrated transmission assessment survey (iTAS), to be used to simultaneously assess onchocerciasis and LF prevalence in areas co-endemic for the two infections that have completed the recommended treatment for one or both infections, and to make decisions on how to proceed. Given the preliminary results, LF MAM can be stopped in Bade, Bekwerra, Gashaka and Karim Lamido LGAs. Subject to availability of resources, an additional round of MAM in schools where antigenemia prevalence is $>2 \%$ is recommended. A further test, following the second round of treatment after the survey, can be undertaken to assess ongoing localized transmission. The State and National authorities should institute adequate surveillance to detect recrudescence. Xeno-monitoring of blackflies in LGAs where the threshold for onchocerciasis elimination by serological assessment has been met in the context of the OR study sites is recommended, followed by strengthening of onchocerciasis MAM and improved supportive supervision particularly in Bekwerra and Gashaka LGAs. Improved synergy with the States and supporting partners on program implementation timelines are recommended to avoid a situation where treatments for schistosomiasis commenced while pupils were being subjected to tests for TAS.

\section{Declarations}

\section{Ethics approval and consent to participate}

Ethical clearance for the study was obtained from the Federal Ministry of Health's Bioethics Committee in the Department of Planning and Research. Details of the procedure were explained to all participants and heads of the schools during social mobilization. Verbal assent of the Head Teachers as well as informed consent from parents and legal guardian of all children that participated were sought. Participation was voluntary.

\section{Consent for publication}

All authors consent to the publication of this research work

\section{Availability of data and material}

All data will be made available to the journal 


\section{Competing interests}

The authors declare no competing interest

\section{Funding}

This work received financial support from the Coalition for Operational Research on Neglected Tropical Diseases, which is funded at The Task Force for Global Health primarily by the Bill \& Melinda Gates Foundation, by the United States Agency for International Development through its Neglected Tropical Diseases Program, and with UK aid from the British people.

\section{Authors' contributions}

Conceived and initiated the article: OC, SOA, AIN, SYA, DE

Prepared tables: OC, SOA, OP, SJ, NG, UZ, IM

Prepared figures: BK, EUF

Wrote the paper: AIN, SYA, SOA, OC, DE, OP, IM, NA, EUF, AUA, BK, SJ, NG, UZ

\section{Acknowledgements}

The authors thank the Director and staff at the NTD Support Center at the Task Force for Global health for logistic support and technical guidance. Technical facilitation from PATH, and United States Centres for Disease Control (CDC) during project implementation are also appreciated. Mission to Save the Helpless (MITOSATH) is appreciated for its exceptional logistic support. The logistic assistance from the country office of the Research Triangle Initiative (RTI) as well as Health and Development Support Programme (HANDS) are valued. We thank the Ministries/Departments of Health, Ministries/Departments of Education and SUBEB offices in the participating States and LGAs for their collaboration and policy direction. Finally, our appreciation goes to: the NTD coordinators and programme staff at State and LGA levels for all the preliminary arrangements and facilitation; Head Teachers and staff of the participating schools for their cooperation; the pupils that registered and were tested; and the drivers and local guides that facilitated movements from one locality to another.

\section{References}

1. Department for International Development (DFID). (2017). Neglected Tropical Diseases Summit 2017, UK Pledge. UK statement delivered by Lord Bates, Minister of State at DFID, on19 April 2017 at the World Health. https://www.gov.uk/government/news/neglected-tropical-diseases-summit-2017-uk-pledge.

2. WHO. African Programme for Onchocerciasis Control: progress report, 2013-2014. Releve epidemiologique hebdomadaire / Section d'hygiene du Secretariat de la Societe des Nations = Weekly epidemiological record /. Health Section of the Secretariat of the League of Nations. 2014;89(49):551-60. Epub 2014/12/09.

3. World Health Organization. (2016). Guidelines for stopping mass drug administration and verifying elimination of human onchocerciasis: criteria and procedures. Geneva (WHO/HTM/NTD/PCT/2016.4).

4. Federal Ministry of Health Nigeria. Neglected Tropical Diseases Nigeria Multi-Year Master Plan 2015-2020. Abuja: FMoH, Nigeria; 2016.

5. APOC. Conceptual and operational framework of onchocerciasis elimination with ivermectin treatment. Ouagadougou: World Health Organization/African Programme for Onchocerciasis Control; 2010.

6. Ojurongbe O, Akindele AA, Adeleke MA, Oyedeji MO, Adedokun SA, Ojo JF, Akinleye CA, Bolaji OS, Adefioye OA, Adeyeba OA. (2015). Co-endemicity of loiasis and onchocerciasis in rain forest communities in southwestern Nigeria. PLoS Negl Trop Dis, 9(3), e0003633. 6. 
7. Amazigo U. The African Programme for Onchocerciasis Control (APOC). Annals of tropical medicine and parasitology. 2008;102 Suppl 1:19-22.

8. Diawara L, Traore MO, Badji A, Bissan Y, Doumbia K, Goita SF, et al. Feasibility of onchocerciasis elimination with ivermectin treatment in endemic foci in Africa: first evidence from studies in Mali and Senegal. PLoS Negl Trop Dis. 2009;3(7):e497.

9. Traore MO, Sarr MD, Badji A, Bissan Y, Diawara L, et al. Proof-of-Principle of Onchocerciasis Elimination with Ivermectin Treatment in Endemic Foci in Africa: Final Results of a Study in Mali and Senegal. PLoSNegl Trop Dis. 2012;6(9):e1825. doi:10.1371/journal.pntd.0001825.

10. Federal Ministry of Health Nigeria. Neglected Tropical Disease Elimination Programme. National Guidelines for Lymphatic FilariasisAssessment With a Framework for Human Capacity Development. Abuja: FMoH, Nigeria; 2019.

11. World Health Organization. (2011) Global Programme to Eliminate Lymphatic Filariasis: Monitoring and epidemiological assessment of mass drug administration: a manual for national elimination programs. Geneva. pp. 22-33.

12. Chu BK, Deming M, Biritwum N-K, Bougma WR, Dorkenoo AM, et al. Transmission Assessment Surveys (TAS) to Define Endpoints for Lymphatic Filariasis Mass Drug Administration: A Multicenter Evaluation. PLoSNegl Trop Dis. 2013;7(12):e2584. doi:10.1371/journal.pntd.0002584.

13. Cao W, Van der Ploeg CPB, Plaisier AP, Van der Sluijs IJ, Lammie PJ. Ivermectin for the chemotherapy of ban-croftian filariasis: a meta-analysis of the effect of single treatment. Tropical Medicine International. 1997; Health2:393-403.

14. Idowu ET, Adeneye AK, Adeleke MA, Sulyman MA, Mafe MA. Endemicity of onchocerciasis in some communities in Taraba State, Nigeria, following long term treatment with ivermectin. The Zoologist. 2013;11:21-8.

\section{Figures}

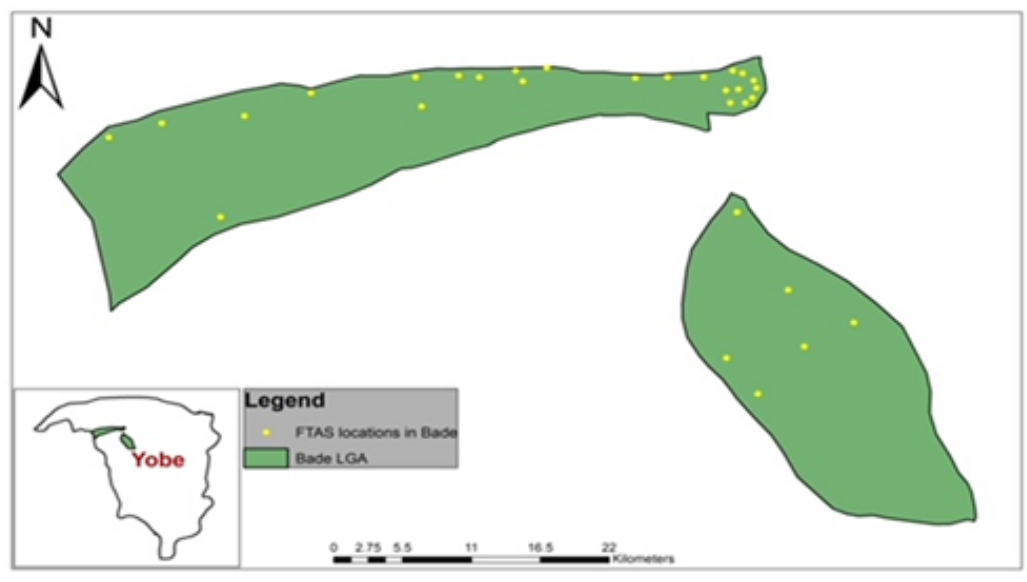

\section{Figure 1}

Maps of study sites in Bade LGA (Yobe state). 


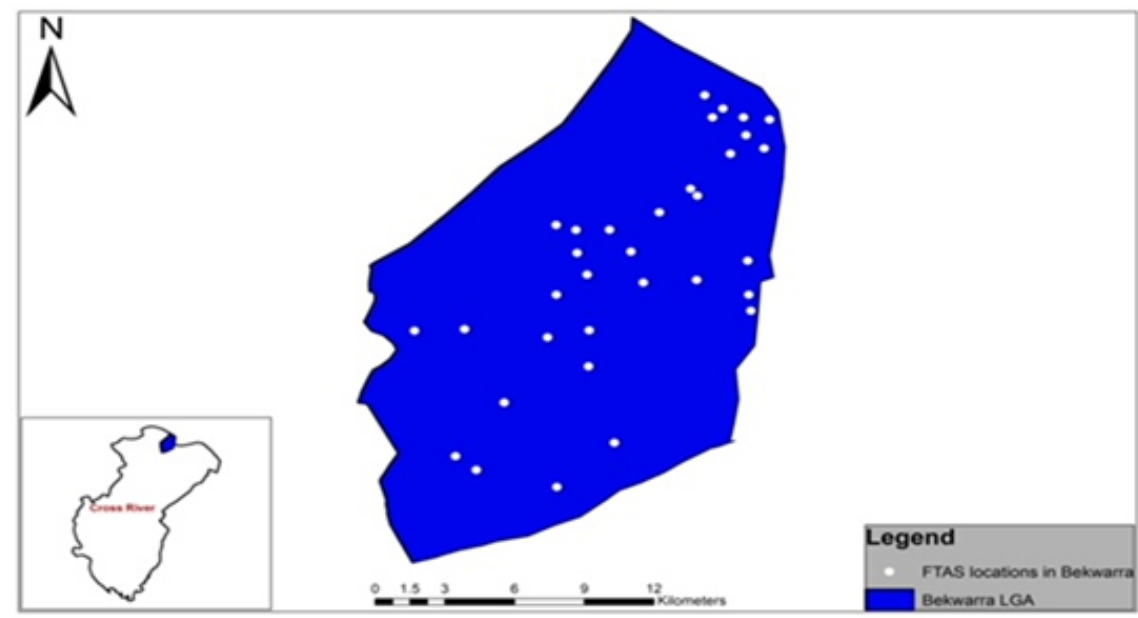

Figure 2

Maps of study sites in Bekwerra LGA (Cross Rivers state).

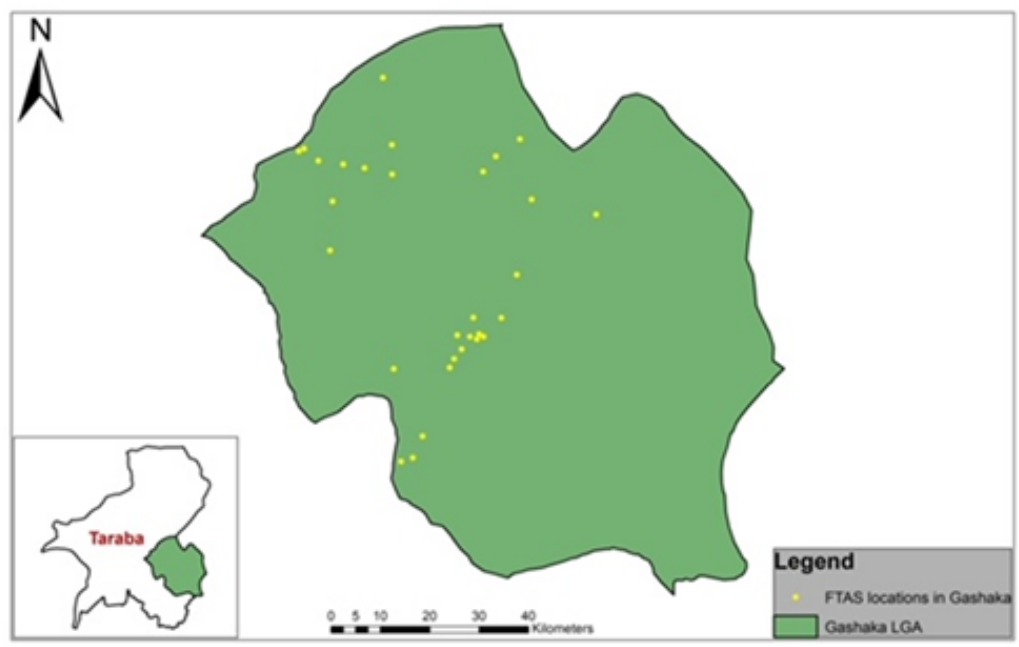

Figure 3

Maps of study sites in Gashaka LGA (Taraba State). 


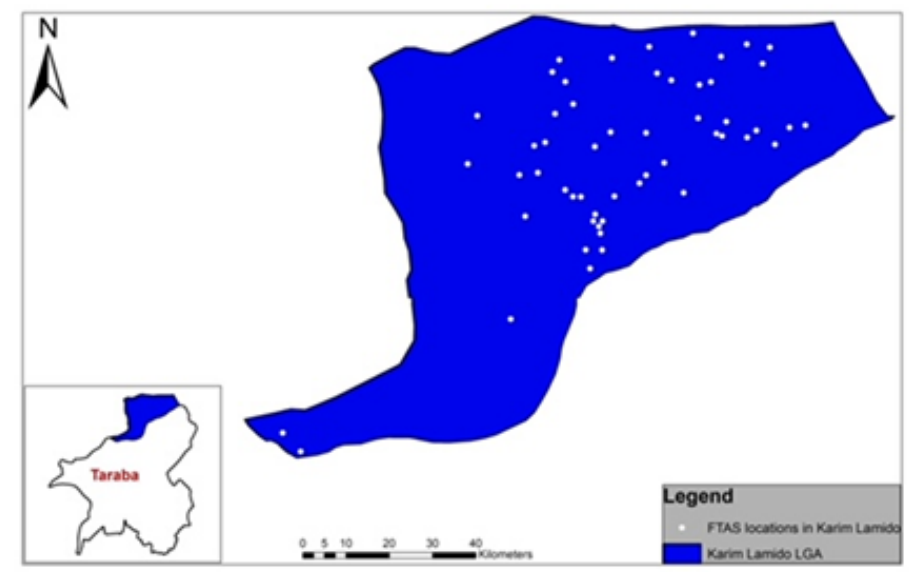

Figure 4

Maps of study sites in Karim Lamido LGA (Taraba State).

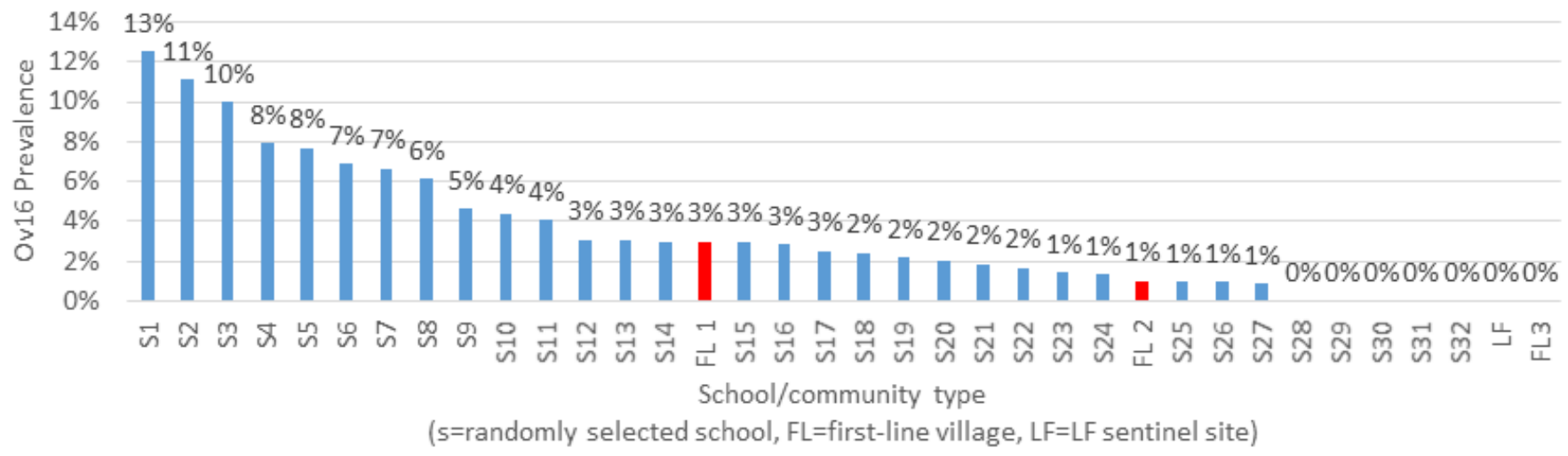

Figure 5

Ov16 prevalence by first-line village, LF sentinel site, or school-based cluster, among 2304 children ages 5-9 in Bekwara LGA, Nigeria, surveyed during pre-iTAS or iTAS in April 2017

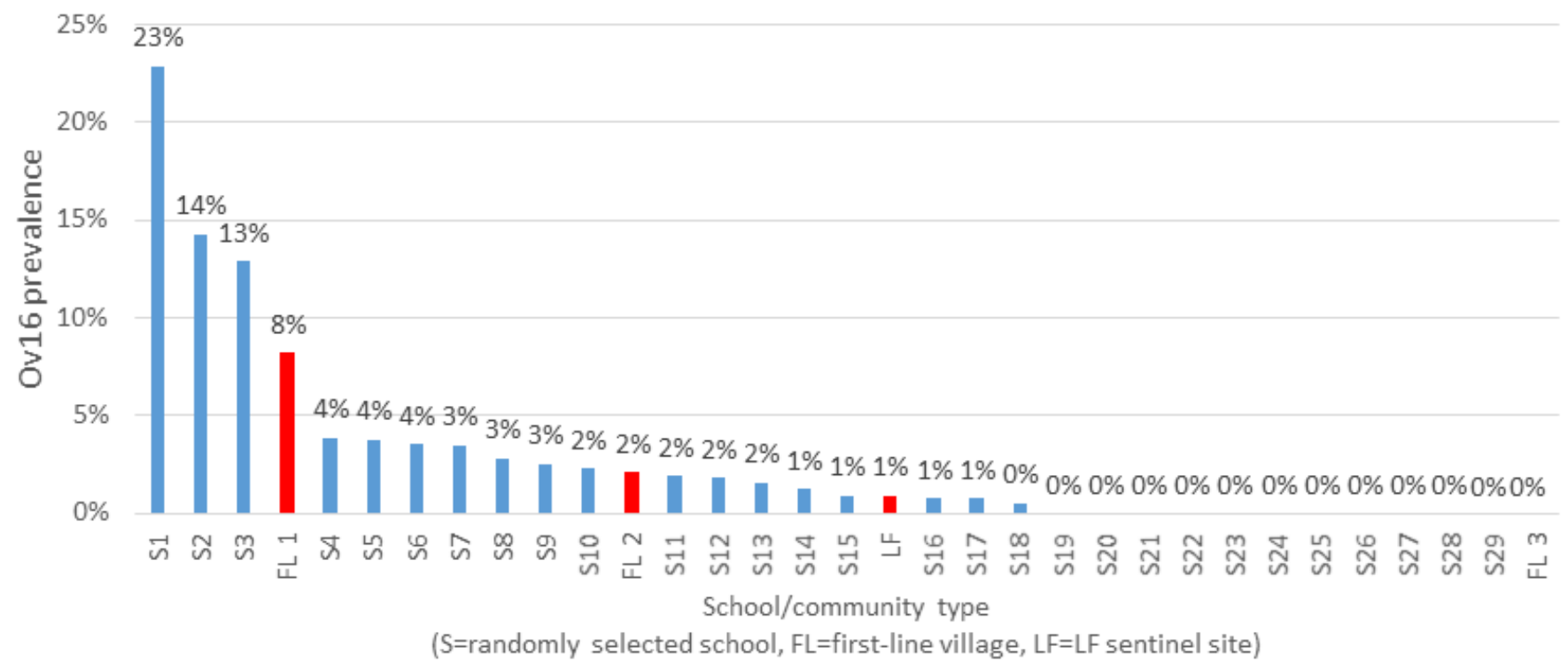

Figure 6 
Ov16 prevalence by first-line village, LF sentinel site, or school-based cluster, among 2484 children ages 5-9 in Gashaka LGA, Nigeria, surveyed during pre-iTAS or iTAS in April 2017 